\title{
DIEGO DE ÁGREDA DOMINÉ: LA ACTIVIDAD ARTÍSTICA DE UN BODEGUERO Y PROPIETARIO DEL SIGLO XIX
}

\author{
DIEGO DE ÁGREDA DOMINÉ: ARTISTIC ACTIVITY \\ OF A WINE MERCHANT AND LANDLORD \\ OF THE $19^{\mathrm{TH}}$ CENTURY
}

Myriam Ferreira Fernández

Universidad Internacional de La Rioja. España

ORCID: 0000-0002-5782-5033

myriam.ferreira@unir.net

\begin{abstract}
Este artículo trata de reconstruir la biografía del comerciante y bodeguero del siglo XIX Diego de Ágreda Dominé, sevillano de nacimiento pero afincado en Jerez de la Frontera. Para ello, se recopila la información publicada sobre él y se aportan nuevos datos procedentes de fuentes documentales y prensa periódica. Se presta especial atención a su actividad artística como pintor aficionado de paisajes, autor de trazas arquitectónicas y primer fotógrafo de la provincia de Cádiz. Además, se aportan nuevos datos sobre su formación, y se añade la información sobre dos descendientes suyos que también desempeñaron tareas artísticas.

Palabras clave: Diego de Ágreda Dominé; siglo XIX; fotografía; Sevilla; Jerez de la Frontera.
\end{abstract}

This paper aims to complete the biography of the wine merchant of the $19^{\text {th }}$ century Diego de Ágreda Dominé, born in Sevilla but settled in Jerez de la Frontera. For this purpose, information published about him is compiled and new information from documentary sources and periodical press is provided. Special attention is paid to his artistic activity, as amateur landscapes painter, architectonical designs author and first photographer of the province of Cadiz. In addition, new data about his formation are provided, and information is given about two of their descendants who also developed artistic tasks.

Keywords: Diego de Ágreda Dominé; $19^{\text {th }}$ century; photograph; Seville; Jerez de la Frontera.

\section{INTRODUCCIÓN}

Diego de Ágreda Dominé fue un sevillano de nacimiento, afincado en Jerez de la Frontera durante la segunda mitad del siglo XIX, que alcanzó cierto 
prestigio por sus facetas de empresario bodeguero, pintor y fotógrafo aficionado, además de por sus iniciativas educativas y artísticas.

La figura de Diego de Ágreda Dominé fue citada tempranamente por Ossorio y Bernard y Ángel Salcedo, quienes precisamente hicieron referencia, aunque someramente, a la faceta artística de Ágreda: su relación con el Liceo Artístico de Madrid y su nombramiento como académico correspondiente de la Real Academia de San Fernando en Jerez de la Frontera ${ }^{1}$. En épocas más recientes, su biografía ha sido enriquecida con las aportaciones de Eduardo Pereiras quien, en su monografía sobre la fotografía en Jerez en el siglo XIX, dedicó un capítulo a Ágreda por ser el primer fotógrafo conocido de la provincia de Cádiz ${ }^{2}$. Muchas de sus aportaciones fueron retomadas y ampliadas por Jesús Caballero Ragel al tratar sobre otro tema: las exposiciones de la Sociedad Económica Jerezana, en la que Ágreda estuvo muy involucrado ${ }^{3}$. Para este artículo, hemos tratado de sintetizar los datos de estas publicaciones, añadiendo nuevas fuentes: datos documentales procedentes de archivos como el Archivo Histórico Diocesano de Logroño, el Archivo General del Arzobispado de Sevilla ${ }^{4}$, el Archivo Municipal de Jerez ${ }^{5}$, el Archivo Histórico Provincial de Cádiz o el Archivo de la Real Academia de San Fernando, así como a recursos documentales online procedentes de la base de datos Pares del Ministerio de Cultura. También se han buscado noticias de prensa que aportaran información sobre el tema, utilizando las bases de prensa histórica de Hemeroteca Digital de la Biblioteca Nacional y de Prensa Histórica del Ministerio de Cultura. Estas búsquedas han permitido aportar nuevos datos sobre la biografía de Diego de Ágreda, como su fecha de nacimiento o datos novedosos sobre su formación artística. Se ha tratado además de contextualizar dicha biografía en sus antecedentes familiares. Nos hemos basado en las publicaciones existentes sobre su familia, en especial a las existentes sobre su abuelo, Simón de Ágreda a propósito de la fundación de las escuelas de su localidad natal, San

${ }^{1}$ OSSORIO Y BERNARD, Manuel: Galería biográfica de artistas españoles del siglo XIX. Madrid, 1868, p. 8; y SALCEDO RUIZ, Ángel: La época de Goya. Madrid, 1924, p. 387.

2 PEREIRAS HURTADO, Eduardo: La fotografía en el Jerez del siglo XIX. Jerez de la Frontera, 2000, pp. 51-ss.

${ }^{3}$ CABALLERO RAGEL, Jesús: Exposiciones y artistas en el Jerez del XIX: las exposiciones de la sociedad económica jerezana, s. e., s. p., pp. 9, 23 y 90-92.

${ }^{4}$ Queremos dar las gracias a Nuria Casquete de Prado y José Antonio Zambrano, de la Institución Colombina, por facilitarnos los documentos relativos al nacimiento de Diego de Ágreda y a su posterior matrimonio.

5 También queremos agradecer a Cristóbal Orellana, del Archivo Municipal de Jerez, por hacernos llegar los documentos relativos a la partida de matrimonio y al testamento de Diego de Ágreda. 
Román de Cameros ${ }^{6}$. Estos datos ayudarán a comprender el ambiente social y económico y la variedad de actividades a las que se dedicó Ágreda. Dentro de esta variedad, se prestará especial atención a lo que se conoce sobre su actividad artística. Y, por último, se hará referencia a dos descendientes suyos que también se dedicaron a actividades de tipo artístico. El hecho de que en 2018 se hayan cumplido 200 años del nacimiento de Ágreda ha supuesto un incentivo para acometer esta labor en estos momentos.

\section{LA FAMILIA ÁGREDA EN LA ANDALUCÍA DE LOS SIGLOS XVIII Y XIX}

Diego de Ágreda Dominé procedía de una familia de origen riojano que se había asentado en Andalucía después de haber prosperado en la carrera de las Indias. Su abuelo, Simón de Ágreda, había nacido en San Román de Cameros, una pequeña localidad situada en una zona montañosa en el suroeste de la actual comunidad autónoma de La Rioja, cuya actividad primordial en el siglo XVIII era la ganadería ${ }^{7}$. Según el Catastro de Ensenada, hacia 1752 vivía en la localidad un "texedor de paños y bayetas" llamado Diego de Ágreda, del estado general. Vivía en "una casa en la calle Real que dizen la plaza con su quarto alto, bajo y principal"s.

Diego de Ágreda había nacido en Torre en Cameros y había contraído matrimonio con Mariana Martínez Cabezón, natural de San Román de Cameros, instalándose en la localidad de su esposa. Tuvieron cuatro hijos: dos mujeres y dos

${ }^{6}$ REINARES MARTÍNEZ, Ernesto y ZAPATER CORNEJO, Miguel: La Escuela de San Román de Cameros y sus fundadores: comerciantes riojanos en el Méjico colonial. Logroño, 1987; ZAPATER CORNEJO, Miguel: "Escuelas de indianos en La Rioja", Tebeto: Anuario del Archivo Histórico Insular de Fuerteventura, 5, 2, 1992, pp. 204-ss.; ZAPATER CORNEJO, Miguel: "Notas sobre la historia escolar del Camero Viejo", Belezos. Revista de cultura popular y tradiciones de La Rioja, 7, 2008, pp. 42-49; MARRODÁN PELLEJERO, Abel y MARRODÁN GIRONÉS, María José: "Niños, escuela y maestros. Apuntes sobre la enseñanza en el Camero Viejo, siglos XVIII y XIX”, Belezos: Revista de cultura popular y tradiciones de La Rioja, 18, 2012, p. 33; y CERRILLO RUBIO, María Inmaculada: "La arquitectura escolar en La Rioja en el siglo XIX: del academicismo al historicismo", Berceo, 165, 2013, p. 51;

7 Sobre Simón de Ágreda, ver REINARES MARTÍNEZ, Ernesto: "Simón de Ágreda y Martínez Cabezón”, en ANES, Gonzalo: Diccionario Biográfico Español. T. I. Madrid, 2009, pp. 557-558; y ZAPATER CORNEJO, Miguel: "Escuelas de indianos...”, op. cit., pp. 204-ss.

${ }^{8}$ AHPLR (Archivo Histórico Provincial de La Rioja), Catastro de Ensenada, San Román de Cameros, Libro de lo personal de seglares, vol. 606, 0008; y Libro de lo raíz de seglares, vol. 607, 0025-0027. 
varones, estos últimos llamados Simón (nacido el 22-10-1748) y Diego (nacido el 7-11-1755) (Figura 1).

En 1763 tuvo lugar el fallecimiento del cabeza de familia. En esos momentos, eran bastantes los hombres de la región que se habían trasladado a América, debido a las mejores condiciones económicas de las Indias frente al escaso rendimiento de la ganadería y sus industrias derivadas en Cameros. De hecho, los hermanos Ágreda tenían un tío, Francisco Martínez Cabezón, asentado en Veracruz (México). Así que, con unos 14 años, Simón viajó a Cádiz desde donde partió a reunirse con su tío, formándose en Veracruz como agente comercial. Diego le siguió pocos años después ${ }^{10}$. La actividad de los dos hermanos se volcó en el comercio marítimo, aunque las labores realizadas fueron muy variadas: viajaban con las mercancías -tenemos constancia de que Simón viajó de la Península a México al menos en 1772, 1776 y 1780-, solicitaban permisos parara la carga y descarga de los productos y ejercían como factores, encargándose de supervisar el embarque de las mercancías ${ }^{11}$. Esta intensa actividad comercial les permitió poseer un capital suficiente como para comprar ellos mismos barcos y convertirse

9 AHDL (Archivo Histórico Diocesano de Logroño), San Román de Cameros, Bautizados (1700-1764), ff. 122v y 144r; AHPLR, Catastro de Ensenada, San Román de Cameros, Libro de lo personal de seglares, vol. 606, 0008; AHN (Archivo Histórico Nacional), Estado-Carlos III, exp. 2224; REINARES MARTÍNEZ, Ernesto y ZAPATER CORNEJO, Miguel: La Escuela de San Román..., op. cit., pp. 19-22; REINARES MARTÍNEZ, Ernesto: "Apuntes para la historia de San Román y su tierra en el Camero Viejo", Berceo, 118-119, 1990, p. 177; y ZAPATER CORNEJO, Miguel: "Escuelas de indianos...", op. cit., pp. 205-206.

${ }^{10}$ REINARES MARTÍNEZ, Ernesto y ZAPATER CORNEJO, Miguel: La Escuela de San Román..., op. cit., pp. 21-23; y REINARES MARTÍNEZ, Ernesto: "Diego de Ágreda Martínez Cabezón”, en ANES, Gonzalo: Diccionario Biográfico Español. T. I. Madrid, 2009, p. 557.

11 MENA GARCÍA, Carmen: "La Casa de la Contratación y el abasto de las flotas de Indias", en ACOSTA RODRÍGUEZ, Antonio; GONZÁLEZ RODRÍGUEZ, Adolfo Luis y VILA VILAR, Enriqueta: La Casa de la Contratación y la navegación entre España y las Indias. Sevilla, 2004, pp. 249-250; y REINARES MARTÍNEZ, Ernesto y ZAPATER CORNEJO, Miguel: La Escuela de San Román..., op. cit., pp. 24-28. Sobre la actividad comercial de los hermanos, ver por ejemplo AGI (Archivo General de Indias), Casa de Contratación, leg. 5516, n. 57 (12/05/1772); leg. 5521, n. 30 (19/04/1776); y leg. 5525, n. 2, r. 26 (13/04/1780); AHFB (Archivo Histórico Foral de Bizkaia), JCR 1635/009 (01/07/1816); RAMOS SANTANA, Alberto (coord.): Dietario del bicentenario. sep. 1810- dic.1812. Cádiz, 2012, p. 36 y 288; ROCA VERNET, Jordi: "La génesis del liberalismo catalán en las Cortes de Cádiz: diputados, comisionados, empleados públicos y comerciantes", en REPETO GARCÍA, Diana: Las Cortes de Cádiz y la Historia Parlamentaria. Cádiz, 2012, p. 513; y LOZANO SALADO, María Dolores: "Dos siglos del comercio gaditano a través de los poderes notariales (1650-1850)", Trocadero: Revista de historia moderna y contemporánea, 3, 1991, p. 57. 
en armadores. Para tener un mayor control de sus actividades comerciales, hacia 1784 los dos hermanos se separaron: Diego quedó en Veracruz, con su tío Francisco y su primo Manuel García Herreros, mientras Simón se instalaba en Cádiz, supervisando personalmente las gestiones comerciales en esta ciudad. Gracias a su intensa actividad, ambos hermanos lograron amasar una gran fortuna, que les permitió recuperar para su familia su condición de hidalguía ${ }^{12}$. Además, comprometidos con la causa liberal, ambos apoyaron política y económicamente la lucha contra el Gobierno francés ${ }^{13}$, con el resultado de que al acabar la guerra Fernando VII otorgó a Diego de Ágreda el título de conde de Casa Ágreda ${ }^{14}$.

Desde esta distinguida posición social y económica, los Ágreda, como otros emigrantes de la época, se sintieron en la obligación de donar parte de ese dinero para una entidad benéfica. En su caso, decidieron crear una escuela de primera enseñanza en su pueblo natal, San Román de Cameros. La iniciativa fue llevada a cabo conjuntamente por los cuatro mercaderes: Martínez Cabezón, García Herreros y los dos Ágreda. En 1787, los cuatro decidieron aportar un capital inicial de 6.000 pesos para el establecimiento de una escuela gratuita de primeras letras. Como Simón se encontraba ya entonces asentado en la Península, fue comisionado por los otros tres para la puesta en marcha de estas escuelas, teniendo por tanto el papel más activo en su creación ${ }^{15}$. Y no fue la única iniciativa educativa en la que participó Simón: también fue miembro de una comisión para la creación de una escuela de comercio en Cádiz ${ }^{16}$.

12 ARCV (Archivo de la Real Chancillería de Valladolid), Registro de ejecutorias, caja 3692, 31 (10/1798).

${ }^{13}$ RAMOS SANTANA, Alberto (coord.): Dietario del bicentenario..., op. cit., p. 288; Representación dirigida a S.M. por el Real Tribunal del Consulado de esta plaza y su junta de gobierno, sobre el reglamento publicado por la superior de confiscos. Cádiz, 1811; y AHN, Estado-Carlos III, exp. 1265 (1805).

${ }_{14}$ AGI, Títulos de Castilla, 2, r.8 (09/07/1811). El título se extinguió tras la muerte de Diego de Ágreda hasta que un sobrino lejano suyo, Tomás Rivero Dávila, logró en 1916 recuperar el título y que se le concediera a su familia. Sin embargo, el hijo de Diego de Ágreda Dominé, José Antonio de Ágreda Pérez Grandallana, juzgó que su rama era más cercana consanguíneamente a Diego de Ágreda Martínez de Cabezón y que debían ser quienes ostentaran el título. Finalmente, el título se le otorgó en 1918, quedando ya ligado a su familia en las siguientes generaciones. La época, Madrid, 5-12-1918, p. 2; y Revista de historia y de genealogía española, Madrid, año 5, no 25, 1-1/28-2-1931, p. 59. Cfr. REINARES MARTÍNEZ, Ernesto y ZAPATER CORNEJO, Miguel: La Escuela de San Román..., op. cit., pp. 29-36.

15 Ver nota 6. Cfr. PEREIRAS HURTADO, Eduardo: La fotografía..., op. cit., p. 54.

${ }^{16}$ BARRIENTOS MÁRQUEZ, María del Mar: "Escuela de Comercio del Consulado Gaditano", Trocadero: Revista de historia moderna y contemporánea, 4, 1992, pp. 9 y 12. 
Simón se casó en Cádiz con Josefa María Jiménez Chantre, natural de Ayamonte ${ }^{17}$. Con ella tendría cuatro hijos: José Antonio, María Bella, Diego (fallecido con 23 años) y Simón (fallecido en su infancia) ${ }^{18}$. El mayor, José Antonio de Ágreda Jiménez-Chantre, nació en Cádiz en 1790, pero acabó trasladándose a Sevilla, donde contrajo matrimonio con Francisca Caraciolo Dominé, originaria de esa ciudad. José Antonio desarrolló en Sevilla una actividad comercial similar a la de su padre en Cádiz. En 1832 aparece matriculado en Sevilla como "del comercio al por mayor" 19 . Además, fue llevando a cabo diferentes actividades políticas. A finales de 1820 fue elegido regidor del Ayuntamiento Constitucional de Sevilla, ocupándose de asuntos relacionados con los presupuestos y el control monetario. En su época, fue definido como "modoso y aplicado" y, aludiendo a su origen no sevillano, se añadía: "no parece sevillano en la locución pero sí en defender aquella casa de moneda" ${ }^{20}$. En 1833 formó parte de la Comisión del Distrito del Sagrario creada por el brote de cólera que afectó a Sevilla ${ }^{21}$. Tal vez por esta labor, además de por la actividad anterior de su padre, en 1834 fue nombrado caballero de la orden de Carlos III ${ }^{22}$. Ese mismo año de 1834, fue elegido procurador por la provincia de Sevilla. Existe la posibilidad de que este cargo le exigiera trasladarse a Madrid, ya que se indica que hacia 1837 la familia estaba asentada en la capital ${ }^{23}$.

En 1840, Simón de Ágreda falleció en Cádiz. Eso hizo que José Antonio se trasladara a esa ciudad con su familia para hacerse cargo de los negocios de su padre. Allí, retomó su actividad política, siendo elegido diputado suplente por Cádiz en las elecciones de $1840^{24}$. Sin embargo, la actividad comercial de Cádiz se encontraba por entonces en declive, mientras que las bodegas familiares que poseían en Jerez de la Frontera, bodegas Ágreda, parecían ser un negocio floreciente

17 AHPCa (Archivo Histórico Provincial de Cádiz), Protocolos notariales, 1829, Testamento de Simón de Ágreda, f. 224 r; y AHN, Estado-Carlos III, exp. 2224, op. cit.

18 AHPCa, Protocolos notariales, Testamento de Simón de Ágreda, 1829, f. 224r.

${ }^{19}$ CARO CANCELA, Diego (dir.): Diccionario biográfico de parlamentarios de Andalucía, 1810-1869. Sevilla, 2010, p. 76.

${ }^{20}$ Ibidem, p. 76.

${ }^{21}$ PEREIRAS HURTADO, Eduardo: La fotografia..., op. cit., p. 53.

${ }^{22}$ AHN, Estado-Carlos III, exp. 2224, op. cit.

${ }^{23}$ AGAS (Archivo General del Arzobispado de Sevilla), Expedientes matrimoniales, 1844, Diego de Ágreda Dominé, f. [10r]-[10v]; y ZAPATER CORNEJO, Miguel: "Escuelas de indianos...", op. cit., p. 206.

${ }^{24}$ CARO CANCELA, Diego (dir.): Diccionario biográfico..., op. cit., p. 76. La candidatura estaba encabezada por Francisco Martínez de la Rosa, al que seguían Javier Isturiz y Antonio Alcalá Galiano. En cuarto lugar figuraba José Antonio de Ágreda. El correo nacional, Madrid, 20-7-1839. 
debido al auge del negocio vinatero. Por ello, José Antonio y su familia se trasladaron de Cádiz a Jerez, donde se instalaron definitivamente ${ }^{25}$.

En Jerez, José Antonio mantuvo su actividad política, siendo concejal del Ayuntamiento de la localidad ${ }^{26}$. Pero principalmente se volcó en el negocio bodeguero familiar, logrando impulsar el crecimiento de las bodegas Ágreda: la prensa nos informa de que entre 1851 y 1856 aumentó la producción de la bodega de 1.988 arrobas (56 botas de vino) a 2.343 arrobas $^{27}$. Es probable que este crecimiento se debiera a las mejoras de infraestructuras en la ciudad que el propio José Antonio impulsó junto con otros bodegueros de la ciudad. Un ejemplo fue la creación e inversión en un proyecto de la Compañía de Navegación del Guadalquivir, para traer reservas de agua desde la fuente de El Tempul a la ciudad de Jerez, proyecto que se llevó a cabo en $1869^{28}$. Asimismo, formó parte de la "Dirección fundadora de la Sociedad Anónima del Ferro-Carril entre Jerez, El Puerto de Santa María y Cádiz", participando incluso en la dirección de estos trabajos con otras personalidades jerezanas, que lograron que el tren empezara a circular en 1854, permitiendo a los bodegueros trasladar por medio del ferrocarril el vino hasta el puerto donde se embarcaba ${ }^{29}$.

En este ambiente, volcado en la industria vinatera, emprendedor y económicamente acomodado, fue en el que nació y creció Diego de Ágreda Dominé.

\section{VIDA Y ACTIVIDAD DE DIEGO DE ÁGREDA DOMINÉ}

Diego de Ágreda Dominé nació en Sevilla el 23 de mayo de 1818, hijo, como hemos visto, de José Antonio de Ágreda y de Francisca Caraciolo Dominé. Fue bautizado al día siguiente en la parroquia del Sagrario de la capital sevillana ${ }^{30}$. Tras pasar su infancia en Sevilla, hacia 1836 la familia se trasladó, como ya hemos indicado, a Madrid.

En Madrid encontramos la primera referencia del interés por las artes de la familia Ágreda. En el curso 1836-1837, tanto Diego de Ágreda como su hermano Gonzalo aparecen inscritos en la Sala de Principios de la Escuela de Dibujo instalada en el antiguo convento de la Trinidad, dependiente de la Real Academia

${ }^{25}$ MARTÍN RODRÍGUEZ, Manuel: "Pluralidad de bancos de emisión en la Andalucía liberal (1835-1868): dos textos jerezanos”, Revista de estudios regionales, 107, 2016, p. 244.

${ }^{26}$ PEREIRAS HURTADO, Eduardo: La fotografí..., op. cit., p. 54.

27 La Nación, Madrid, 9-1-1851; La España, Madrid, 9-9-1852, p. 1; La España, Madrid, 11-5-1853, p. 1; y La Discusión, Madrid, 25-11-1856.

${ }_{28}$ CABALLERO RAGEL, Jesús: Exposiciones y artistas..., op. cit., pp. 9, 23 y 90-92.

29 Ibidem, pp. 9 y 90-92; y TORREJÓN CHAVES, Juan: "Cádiz y los orígenes del ferrocarril en España”, en IV Congreso Historia Ferroviaria. Málaga, 2006, p. 27.

${ }^{30}$ AGAS, Parroquia del Sagrario, Bautizados, lib. 75, f. 136r. 
de Bellas Artes de San Fernando ${ }^{31}$. Los jóvenes, sin embargo, no aparecerán ya matriculados en los siguientes años, por lo que su formación en esta escuela fue breve. Sin embargo, sí que mantuvieron su relación con el ambiente artístico de la capital participando en las tertulias del Liceo Artístico y Literario, "en cuyas sesiones prácticas y de competencia tomaba parte muy activa" 32 . De hecho, Diego fue elegido secretario de la sección de pintura en 1839, con apenas 20 años. Ese año ofreció un "cuadrito al óleo" ${ }^{33}$ para que fuera rifado junto con otras obras, con el fin de donar los beneficios al pintor Antonio Esquivel, que había perdido la vista a consecuencia de un "humor herpético" 34.

Su vinculación con el ambiente artístico académico de Madrid dio lugar a un error repetido por varios de sus biógrafos: que Diego sería pariente -sobrino según Ossorio y hermano según Salcedo-del escultor Esteban de Ágreda ${ }^{35}$. En realidad, no parece que hubiera vinculación familiar entre ambos personajes, a pesar de que ambos compartían apellido y de que en ambos casos procedían de familias que descendían de La Rioja ${ }^{36}$.

Hacia 1840, Diego se debió trasladar con el resto de su familia a Cádiz y luego a Jerez. Además, tal vez por necesidades de su negocio, su padre también realizó algunos viajes al extranjero en los que llevó a sus hijos consigo ${ }^{37}$.

El 30 de septiembre de 1844 contrajo matrimonio en Jerez con Petra (o Petrola) González de Grandallana. Petra era natural de Jerez, hija de Francisco Grandallana, brigadier, y de Petra Angulo ${ }^{38}$. El novio llegó al matrimonio con una dote destacada: 1.000 duros por parte de su padre y 2.000 por parte de su madre. Petra, sin embargo, no aportó ninguna dote al matrimonio, aunque tiempo después pudo aportar 50.000 reales por la herencia recibida de su tío Francisco Simón de Grandallana ${ }^{39}$. El matrimonio tuvo tres hijos: María Josefa, José Antonio

${ }^{31}$ ARABASF (Archivo de la Real Academia de Bellas Artes de San Fernando), 1-2212. Matrícula. 1832-1856, f. 6v.

${ }^{32}$ La Academia: revista de cultura hispano portuguesa latino-americana. T. I. Madrid, 15-4-1877, p. 4; y CABALLERO RAGEL, Jesús: Exposiciones y artistas..., op. cit., pp. 90-92.

33 Revista contemporánea, Madrid, n. 49, 1-1884, p. 296.

${ }_{34}$ Diario oficial de avisos de Madrid, Madrid, 26-8-1883, p. 4.

${ }^{35}$ OSSORIO Y BERNARD, Manuel: Galería biográfica ..., op. cit., p. 8; y SALCEDO RUIZ, Ángel: La época..., op. cit., p. 387. Cfr. PARDO CANALÍS, Enrique: "Acotaciones a un estudio sobre Esteban de Ágreda”, Archivo Español de Arte, 25, 1952, pp. 249-256.

${ }^{36}$ FERREIRA FERNÁNDEZ, Myriam: Los Ágreda. La evolución de la escultura del taller barroco a la Academia neoclásica. Logroño, 2014.

37 AGAS, Expedientes matrimoniales, 1844, Diego de Ágreda Dominé, f. [10r].

38 AMJ (Archivo Municipal de Jerez), Matrimonios Civiles, 1848, $\mathrm{n}^{\circ} 176$.

39 AMJ, Testamentos, Manuel García de Acuña y Sánchez, 1865, ff. 1589-1594; 1590. 
y Petra, además de un niño llamado también José Antonio que falleció con 5 meses y una niña llamada Luisa Gonzaga que murió con 15 años ${ }^{40}$.

El 8 de noviembre de 1865 murió su padre, José Antonio de Ágreda. Diego decidió hacer testamento para incluir la herencia paterna entre los bienes que legaría a sus hijos en caso de morir ${ }^{41}$. Pocos meses después, en 1866 fallecía también su hermano Gonzalo, con solo 42 años. Diego quedó como responsable de la actividad de su padre como hacendado y bodeguero.

Desde este cargo, Diego dio un fuerte impulso a las bodegas Ágreda. Adquirió una nueva casa en la entonces calle Collantes para instalar en ella las oficinas de la empresa además de su casa particular. Además, Diego poseía otra bodega en la calle Antonia de Dios (hoy Sánchez Ayala) y una viña, llamada Las Cañas, en el pago Balbaína, cercano a El Puerto de Santa María ${ }^{42}$. Para aumentar el prestigio de la bodega, participó en diversas iniciativas promocionales, siendo la más destacada su participación en la Exposición General de Viena en 1873, donde obtuvo una medalla al progreso por sus vinos ${ }^{43}$, la misma que González Byass y compañía. El marqués del Duero, que se ocupaba de los artículos para la prensa sobre esta Exposición, calificó su jerez como "delicioso" y añadió que fue "calurosamente aplaudido y vitoreado". Aun así, se quejó de que era difícil hallar mercado en Austria porque en este país, aunque "reconocían la bondad de nuestros vinos de Jerez [...] todos les parecían fuertes"

Además de esta labor de difusión, Diego también trató de mejorar las infraestructuras que facilitaran la comercialización de sus productos. Apoyó, junto con su padre, la creación del ferrocarril Jerez-Puerto de Santa María-Cádiz, e incluso fue un paso más allá sugiriendo con otros bodegueros la necesidad de crear un tren urbano que atravesara las principales bodegas para trasladar las mercancías desde su interior. Tras diversos debates sobre este tema en los que Ágreda participó activamente, hacia 1870 el tren urbano de Jerez se convirtió en una realidad ${ }^{45}$.

Gran parte de las iniciativas para mejorar las infraestructuras de la ciudad las canalizó a través de la Sociedad Económica Jerezana, en la que entró a formar parte el 7 de enero de 1852. Como agradecimiento por este nombramiento,
40 Ibidem, f. 1590.
${ }^{41}$ Ibid., f. 1591v.
${ }^{42}$ CABALlERO RAGEL, Jesús: Exposiciones y artistas..., op. cit., pp. 90-92 y 149.
${ }^{43}$ La gaceta industrial, Madrid, 13-11-1873, p. 1.
${ }^{44}$ MARQUÉS DEL DUERO (Don Manuel de la Concha): "Los vinos en la Exposición de Viena", Revista de España, tomo XXXVI, enero y febrero 1874, p. 187.

${ }^{45}$ PEREIRAS HURTADO, Eduardo: La fotografía..., op. cit., p. 54; CABALLERO RAGEL, Jesús: Exposiciones y artistas..., op. cit., pp. 9, 13 y 90-92; y ALADRO PRIETO, José Manuel: "El tren del vino. El ferrocarril urbano de Jerez de la Frontera como instrumento de puesta en producción de la ciudad mercantil", en IV Congreso Historia Ferroviaria..., op. cit. 
Diego envió a la Sociedad un tomo con las obras de Byron, lo que demuestra su aprecio por la cultura europea y una cierta tendencia hacia el romanticismo que se verá en otros momentos de su vida ${ }^{46}$. En la Sociedad Económica formó parte de la junta provincial de agricultura, de la que llegó a ser vocal secretario. En 1856 lo encontramos ya ejerciendo el cargo de contador, que desempeñará por lo menos hasta $1865^{47}$.

Desde esta Sociedad, Diego impulsó también activamente iniciativas educacionales, en la línea de la actividad de su padre y de su abuelo. Sabemos que a lo largo de su vida trató de poner en marcha una academia artística en Jerez, impulsando hasta tres iniciativas diferentes que se vieron frenadas por la difícil situación política del siglo XIX y por la oposición de la cercana Escuela de Bellas Artes de Cádiz ${ }^{48}$. Ante la falta de un centro educativo directamente dirigido a las artes, será la propia Real Sociedad Jerezana la que decida promover el cultivo de las artes a través de exposiciones artísticas. En concreto, se han documentado tres exposiciones organizadas por la Real Sociedad: en 1856, en 1858 y en 1862. Y, según Caballero Ragel, Diego de Ágreda estuvo involucrado en las tres exposiciones: en 1856 participó como artista, en la de 1858 fue vocal-secretario de la comisión organizadora y, por último, en la exposición celebrada en 1862, Diego actuó como parte del jurado ${ }^{49}$.

Su interés por la educación también le llevó a intentar dar un uso didáctico a dos de sus aficiones: la botánica y la zoología ${ }^{50}$. Así, en 1856 presentó en la exposición de la Sociedad Económica una colección de plantas exóticas de Europa y África cultivadas en su propia propiedad, además de unos pollos híbridos procedentes del cruce entre gallinas españolas y gallinas de la Conchinchina. En 1858 presentó, también en la exposición de la Sociedad Económica, 147 muestras de madera cortadas en los alrededores de Jerez, además de simientes nuevamente exóticas. En 1861, recogió más de 200 insectos diferentes en su finca que llevó al Instituto provincial para su clasificación por la cátedra de Historia

${ }^{46}$ PEREIRAS HURTADO, Eduardo: La fotografía..., op. cit., p. 53.

${ }^{47}$ CABALLERO RAGEL, Jesús: Exposiciones y artistas..., op. cit., pp. 66, 74-75 y 90-92; Guía de forasteros en Madrid. Madrid, 1858, p. 498; Guía de forasteros en Madrid. Madrid, 1859, p. 510; Guía de forasteros en Madrid. Madrid, 1860, p. 522; Guía de forasteros en Madrid. Madrid, 1864, p. 729; y Guía de forasteros en Madrid. Madrid, 1865, p. 732. Sobre esta sociedad, ver ENCISO RECIO, Luis Miguel: Las sociedades económicas en el Siglo de las Luces. Madrid, 2010, p. 416; e IGLESIAS RODRÍGUEZ, Juan José: "Ilustración y Sociedades Económicas en la provincia de Cádiz", Studia Historica: Historia Moderna, 28, 2006, pp. 337-357.

${ }^{48}$ CABALLERO RAGEL, Jesús: Exposiciones y artistas..., op. cit., pp. 86, 94 y 282289.

49 Ibidem, pp. 66, 90-92, 150 y 193.

${ }^{50}$ Sobre este aspecto, ver PEREIRAS HURTADO, Eduardo: La fotografía..., op. cit., pp. 54-56. 
Natural. Incluso intentó crear un Museo de Ciencias Naturales, utilizando para ello el viejo palacio de Villapanés, aunque esta iniciativa tampoco dio frutos. Sus conocimientos botánicos le llevaron también a enviar una carta al periódico sugiriendo qué tipos de árboles serían los más apropiados para plantar en las calles de Jerez.

Además, a él correspondió finalizar la iniciativa que más prestigio dio a su abuelo: la creación de las escuelas de San Román de Cameros. Tras la muerte de Simón, fue su hijo José Antonio quien realizó un seguimiento más directo de la puesta en marcha e incluso, tras la aprobación de la Ley Moyano en 1857, impulsó la ampliación de los edificios y la creación de una escuela de niñas que complementara la de varones. Con la muerte de este, fue Diego quien hizo entrega de la fundación al Patronato de las Escuelas en 1868, trasladándose personalmente a San Román para esta ocasión ${ }^{51}$.

Pero las iniciativas filantrópicas que impulsó no se limitaron al campo educativo: también consta su impulso del asilo de San José de Jerez, donde se recogían los ancianos menesterosos, el envío de un donativo económico, a través de la Sociedad Económica, a Narciso Monturiol para ayudarle en su proyecto de construcción de un submarino o la organización de una rifa de obras de arte en 1859 destinada a sufragar el monumento a Murillo en Sevilla. Para esta iniciativa, Ágreda se asoció con el pintor José María Bracho y Murillo, sevillano, como él mismo, de nacimiento, profesor de dibujo en Jerez y discípulo del antiguo conocido de Ágreda Antonio Esquivel ${ }^{52}$.

\section{ACTIVIDAD ARTÍSTICA DE DIEGO DE ÁGREDA DOMINÉ}

Como indicábamos, Diego de Ágreda inició su formación artística en Madrid, asistiendo al aula de principios de la Real Academia de San Fernando, donde los alumnos aprendían a dibujar la figura humana a partir de cartillas. Sin embargo, esta formación parece insuficiente para las obras que posteriormente Diego realizaría, por lo que no es descartable que también recibiera formación artística bien en Sevilla, bien en Cádiz, bien por parte de algún instructor personal. Aun así, nunca llegó a recibir una formación reglada completa en el ámbito artístico, de modo que siempre fue considerado un artista "aficionado" 53 .

Las obras que conocemos realizadas por él son mayoritariamente obras de pintura. Así, como indicábamos previamente, sabemos que en 1839 realizó un

${ }^{51}$ REINARES MARTÍNEZ, Ernesto y ZAPATER CORNEJO, Miguel: La Escuela de San Román..., op. cit., pp. 69-71; y ZAPATER CORNEJO, Miguel: "Notas sobre la historia escolar...", op. cit., p. 47.

52 PEREIRAS HURTADO, Eduardo: La fotografí...., op. cit., pp. 54-56; y Adelante: revista salmantina de ciencias, artes, literatura é intereses materiales, 90, 3-3-1861, p. 4.

${ }^{53}$ PEREIRAS HURTADO, Eduardo: La fotografía..., op. cit., pp. 52. 
cuadrito al óleo subastado en beneficio de Esquivel y que dos años después, en 1841, expuso "dos cuadritos" en la exposición de la Academia de Bellas Artes de Cádi $^{54}$. En ninguno de los dos casos conocemos el tema representado, aunque podría tratarse de paisajes: Pereiras Hurtado recoge testimonios de autores que se refieren a él como "pintor paisajista de gran mérito" 55 .

Tenemos referencias a que Diego realizó también diseños arquitectónicos. En 1856, como ya hemos señalado, participó en la exposición artística de la Sociedad Económica Jerezana, con dos obras: un proyecto de un casino y un plano arquitectónico de una casa de campo. El primero presenta el trazado de una planta, alzado y corte interior del casino de Isabel II. El segundo representa la fachada, área, cortes y perfiles de una casa de campo en la viña propia del señor Ágreda, la cual según Caballero Ragel se corresponde con la finca Las Palmas, situada en el pago de Balbaína ${ }^{56}$. Además, en otro evento, la feria ganadera de Caulina, se pidió a Diego de Ágreda que revisara y reformara los diseños que el pintor Juan Coli había realizado para la Caseta Nacional, tal vez por ser Coli pintor escenógrafo y no arquitecto ${ }^{57}$.

Estos proyectos nos muestran que Diego también poseía formación arquitectónica, una formación que traslucirá en alguna de sus actividades. Por ejemplo, en 1858 decidió afrontar algunos cambios en la casa que había adquirido en la calle Collantes. El principal cambio fue la construcción de un patio interior de estilo neomudéjar, inspirado en el Salón Dorado de la Alhambra de Granada (Figuras 2-3). La elección por este estilo muestra su tendencia hacia el romanticismo y el historicismo. El propio Diego diseñó los motivos ornamentales que debían utilizarse para la decoración del patio, como azulejos, yeserías y mocárabes, aunque encargó la obra al arquitecto sevillano José Martínez. Su iniciativa en esta reforma quedó reflejada en un altorrelieve realizado en el mismo patio: "Bajo la inspección de D. Diego de Ágreda dibujó y talló estos arabescos José Martínez, natural de Sevilla. Año de 1858". El patio nazarí neomudéjar diseñado por Ágreda llegó a ser tan popular que Jean Laurent quiso fotografiarlo en 1879 para incluirlo en su serie de monumentos locales. Como anécdota, sabemos que el 19 de marzo de 1866 cayó un rayo sobre la casa que ocasionó diversos destrozos, aunque al llegar a la cocina "se partió en dos, dejando entre ambas milagrosamente ilesos al cocinero y a un niño que allí se encontraba" 58 .

Poco después, hacia 1870, Diego culminó la obra con la construcción de unos ricos jardines y, en ellos, una gran fuente con figuras de niños-delfines, hechos de

${ }^{54}$ El Eco del comercio, Madrid, 5-10-1841, p. 2.

${ }_{55}$ PEREIRAS HURTADO, Eduardo: La fotografia..., op. cit., p. 53.

${ }^{56}$ CABALLERO RAGEL, Jesús: Exposiciones y artistas..., op. cit., pp. 90-92 y 149.

57 Ibidem, p. 211.

${ }_{58}$ Ibid., pp. 15 y 91; y La Abeja montañesa: Periódico de intereses locales, Santander, 27-3-1866, p. 2. 
hierro, que lanzaban chorros de agua ${ }^{59}$. Aunque en este caso no consta la participación de Diego en esta iniciativa, es bastante posible que también fuera el autor del diseño y que supervisara la construcción del mismo.

Además de la pintura y la arquitectura, la otra actividad artística que ejerció Diego de Ágreda fue la de fotógrafo, hasta el punto de ser considerado "uno de los primeros fotógrafos españoles" ${ }^{\circ 0}$. Al parecer, en septiembre de 1841 se celebraba en Cádiz la Exposición Artística de Otoño, organizada por la Academia Gaditana de Nobles Artes. Ágreda se trasladó desde Jerez para presentar dos cuadritos y, como obra novedosa, en la sección de Arquitectura, dos daguerrotipos realizados por él mismo, que representaban dos edificios gaditanos ${ }^{61}$. La prensa local recogió la noticia con admiración: "Es de rigorosa justicia elogiar cual se merece el primer producto gaditano del Daguerrotipo dispuesto por don Diego de Agreda" 62

Se trata de una fecha muy temprana: las primeras fotografías en España datan de 1839, solo dos años antes. Pereiras Hurtado ha tratado de explicar cómo pudo Diego tener tan pronto conocimiento y dominio del daguerrotipo, suponiendo que tal vez le fue regalado por Gautier hacia 1840. En efecto, el escritor francés Teófilo Gautier viajó en 1840 a Andalucía, trayendo consigo un daguerrotipo del que sin embargo no hace mención hacia el final del viaje. Gautier relata que en Granada trabó amistad con el hijo de un "rico vinatero de Jerez", quien le dio una recomendación para cuando visitara a su padre en su ciudad. Basándose en estos datos, Pereiras sugiere que ese amigo que Gautier hizo en Granada podía ser el propio Diego de Ágreda, hijo efectivamente de un vinatero de Jerez. Y añade otro dato que corrobora su teoría: que Gautier recordaba haber estado bebiendo vino de Jerez en el interior mismo de la Alhambra, en el Patio de los Leones, donde expresó la posibilidad de "repetir el Patio de los leones en una finca mía [...] si yo fuese millonario", tal y como Diego de Ágreda hizo en el patio de su propia residencia ${ }^{63}$.

La hipótesis de Pereira es coherente y bien razonada, aunque esa imagen de Diego de Ágreda como un joven bohemio que bebe vino con amigos extranjeros no concuerda con otros testimonios que describen a Diego como un joven sometido a la actitud protectora de su padre, José Antonio. Este, al testificar poco antes de la boda de su hijo, indicaba "que constantemente D. Diego de Ágreda y sus demás hijos han estado bajo la más inmediata vigilancia, de consiguiente en ninguno de los puntos que han residido han contraído ni podido contraer esponsales

${ }^{59}$ CABALlERO RAGEL, Jesús: Exposiciones y artistas..., op. cit., pp. 22-23.

${ }^{60}$ Ibidem, p. 270.

${ }^{61}$ PEREIRAS HURTADO, Eduardo: La fotografía..., op. cit., p. 15.

${ }^{62}$ Ibidem, pp. 51-52; y El Eco del comercio, Madrid, 5-10-1841, p. 2.

${ }^{63}$ PEREIRAS HURTADO, Eduardo: La fotografia..., op. cit., p. 58. 
ni ninguna otra relación" ${ }^{4}$, y un amigo suyo, Cristóbal Salcedo, afirmaba que José Antonio "es tan vigilante y celoso sobre la conducta de sus hijos D. Diego y D. Gonzalo q[u]e cuando ha estado con ellos en Madrid y aun ha viajado $\mathrm{p}$ [o] $r$ el estrangero no los ha separado un instante solo de su vista hasta el punto de dormir en la misma habitación $\mathrm{q}[\mathrm{u}] \mathrm{e}$ ellos siendo su vigilancia tan continua y estraordinaria $\mathrm{q}[\mathrm{u}] \mathrm{e}$ considero absolutamente imposible el $\mathrm{q}[\mathrm{u}] \mathrm{e}$ hayan tenido ningún género de relación con persona alguna sin el conocimiento de su padre" ${ }^{65}$. Queda por tanto la duda de si Diego obtuvo su daguerrotipo por medio de Gautier o por otro medio.

Para terminar con este apartado, podemos indicar que el prestigio que Ágreda alcanzó con estas iniciativas artísticas y su anterior vinculación con el entorno artístico madrileño debieron ser las causas de que, a principios de 1868, Diego fuera nombrado por la Real Academia de Bellas Artes de San Fernando en Madrid académico corresponsal en Jerez. El nombramiento suponía la responsabilidad de promover las artes y defender el patrimonio de su localidad ${ }^{66}$.

\section{LA ACTIVIDAD ARTÍSTICA DE LOS DESCENDIENTES DE DIEGO DE ÁGREDA DOMINÉ}

Diego de Ágreda Dominé murió en Jerez el 5 de mayo de 1876, a los 58 años de edad ${ }^{67}$. Para entonces, su esposa Petra había fallecido ya, por lo que se encontraba viudo. Sus bienes, según su testamento, pasaron a sus hijos ${ }^{68}$. Sin embargo, poco después de la muerte de Diego, la crisis económica en el sector vinícola, provocada sobre todo por la plaga de filoxera, afectó fuertemente a las bodegas Ágreda, que acabaron cerrándose. En estas condiciones, su hijo mayor, José Antonio, vendió en 1889 la Casa del Jardín a las religiosas de la Compañía de María, que abrieron en ella un colegio que todavía perdura en la actualidad ${ }^{69}$.

Sin embargo, aunque las siguientes generaciones no mantuvieron su negocio vitivinícola, hay otro aspecto en el que algunos descendientes de Diego se mostraron continuadores suyos: su actividad artística. En concreto, podemos citar el caso de dos de sus nietos: el pintor Manuel González Ágreda y el arquitecto José Antonio Ágreda González.

${ }^{64}$ AGAS, Expedientes matrimoniales, Diego de Ágreda Dominé, 1844, f. [1v].

${ }^{65}$ Ibidem, ff. [9v]-[10r].

${ }^{66}$ ARABASF, 1-53-1. Secretario general. Académicos correspondientes (España y extranjero), 30/03/1860. Cfr. OSSORIO Y BERNARD, Manuel: Galería biográfica..., op. cit., p. 8.

${ }^{67}$ AHDJ (Archivo Histórico Diocesano de Jerez), San Miguel, Libro de difuntos $n^{\circ}$ 44, f. 83; y CABALLERO RAGEL, Jesús: Exposiciones y artistas..., op. cit., pp. 90-92.

68 AMJ, Testamentos, Manuel García de Acuña y Sánchez, 1865, ff. 1589r-1593r.

${ }^{69}$ CABALLERO RAGEL, Jesús: Exposiciones y artistas..., op. cit., p. 91. 
Manuel González Ágreda era hijo de María Josefa de Ágreda y de Manuel González de Soto, este último hijo de Manuel María González Ángel, marqués de Bonanza y fundador de las bodegas González Byass ${ }^{70}$. Manuel se formó en la Academia de Dibujo que su propio padre había fundado en el antiguo convento de Santo Domingo, donde había reunido su colección de obras de arte. Allí tuvo como maestro al pintor Rodríguez Losada, antes de trasladarse a Sevilla, donde fue discípulo de Jiménez Aranda, y luego en París, donde acudió a la prestigiosa Academia Julian ${ }^{71}$. Su pintura se orientó hacia el realismo costumbrista, muy extendido entre finales del siglo XIX y principios del siglo XX. Sus obras representan retratos, paisajes y personajes populares, como mendigos, gitanas, niños, muchachas de pueblo, etc. ${ }^{72}$. Con dichas obras participó en diferentes eventos: en la exposición local de 1904, donde consiguió mención honorífica por sus cuadros, la exposición de París de 1914 o las exposiciones de artistas organizadas por el Ateneo jerezano en 1930 y $1933^{73}$. Además, fue notable su labor docente en la Escuela de Artes y Oficios de Jerez, finalmente inaugurada en 1911, donde fue profesor de la asignatura de "Dibujo artístico y elementos de historia del Arte", con un sueldo anual de 2.500 pesetas $^{74}$. Por otro lado, gracias a su buena posición social y económica, trabó contacto con destacados pintores de la época, como Sorolla, a quien invitó a pintar en su finca y con quien mantuvo correspondencia posteriormente ${ }^{75}$.

Más interesante es la figura de José Antonio de Ágreda González, primo-hermano del anterior, hijo de José Antonio de Ágreda y de María Luisa González, también hija del marqués de Bonanza. José Antonio nació en Jerez de la Frontera

${ }^{70}$ DE LA BANDA Y VARGAS, Antonio: "La pintura jerezana en el siglo XIX", $A r$ chivo Español de Arte, 273, 1996, p. 95; y CABALLERO RAGEL, Jesús: "La galería de retratos de directores y patronos del instituto Padre Luis Coloma de Jerez", Revista Historia de Jerez, 16-17, 2004, pp. 8-9.

${ }^{71}$ Ibidem; y DE LA BANDA Y VARGAS, Antonio: "La pintura jerezana...", op. cit., p. 95.

72 DE LA BANDA Y VARGAS, Antonio: "La pintura jerezana...”, op. cit., p. 95. Caballero Ragel incluye un inventario de sus cuadros expuestos en 1910 en el Museo de Santo Domingo, con su nombre y su valoración. CABALLERO RAGEL, Jesús: Exposiciones y artistas..., op. cit., p. 53.

${ }^{73}$ CABALLERO RAGEL, Jesús: "La galería de retratos de directores y patronos...", op. cit., pp. 202-203; y CABALLERO RAGEL, Jesús: Exposiciones y artistas..., op. cit., p. 36.

${ }^{74}$ CABALLERO RAGEL, Jesús: "La galería de retratos de directores y patronos...", op. cit.; y CABALLERO RAGEL, Jesús: "Antecedentes artísticos y pedagógicos de la Escuela de Artes y Oficios de Jerez”, en 100 TAY TAN TAS Carpas. Cádiz, 2010. De hecho, aun hoy existe en Jerez una calle dedicada al "Pintor Ágreda González".

${ }^{75}$ Museo Sorolla, CS2427, 20-10-1914. 
el 24 de marzo de $1881^{76}$. Hacia 1899, con apenas 18 años, se trasladó a Madrid para estudiar la carrera de Arquitectura en la Facultad de Ciencias de la Universidad Central, finalizando sus estudios en $1903^{77}$. En los siguientes años se conocen diversos diseños suyos en edificios de viviendas de Madrid: tenemos noticias de que trabajó en el palacete de Santo Mauro, obra de Juan Bautista Lázaro (1899), que construyó los edificios de calle Lista 10 (hoy Ortega y Gasset) (1914), Almagro 15 (1916), San Bernardo 67 (1925), San Bernardo 112 (1927) y Benito Gutiérrrez 12 (1929) (que no se conserva hoy en día) y que presentó un anteproyecto para el edificio del Círculo de la Unión Mercantil, que sería finalmente realizado por Luis y Joaquín Sainz de los Terreros (Figuras 4-5). Además, entre 1927 y 1929 construyó para su ciudad natal un pabellón destinado a las bodegas González Byass ${ }^{78}$.

Más allá de esta actividad en la construcción privada, en 1917 fue nombrado arquitecto de obras públicas, al servicio del Catastro de la riqueza urbana. Tres meses después, en 1918, era destinado a la ciudad de Palencia. Hacia 1944 parece ser que fue nombrado arquitecto jefe de segunda clase, con destino a la Delegación de Madrid ${ }^{79}$.

José Antonio desarrolló un estilo regionalista que recuerda a la obra neomudéjar impulsada por su abuelo en su casa. Sus obras se caracterizan por la abundancia decorativa, con molduras ornamentales y con rejerías de influencia modernista, además de por elementos ornamentales regionalistas, como los azulejos decorativos, encargados al célebre ceramista talaverano Juan Ruiz de Luna. Falleció en Madrid el 13 de julio de $1953^{80}$.

Fecha de recepción: 30 de octubre de 2018

Fecha de aceptación: 5 de febrero de 2019

${ }^{76}$ Boletín Oficial del Estado, Madrid, no 182, 1-7-1846, p. 5297.

77 AHN, Universidad Central, 5209, exp. 4.

78 SÁNCHEZ GONZÁLEZ, Antonio: El arte de la representación del espacio: mapas y planos de la colección Medinaceli. Huelva, 2017, p. 29; MUÑOZ DE PABLO, María José: Chamberí, s. XIX: trazas en la ciudad. Tesis Doctoral, Universidad Politécnica de Madrid, 2008, pp. 372, 381 y 389; Arquitectura y construcción, Barcelona, 262, mayo 1914, pp. 118 y 119; La construcción moderna, Madrid, 12, 30-6-1916, p. 93; PALIZA MONDUATE, María Teresa: "Los ingenieros y la práctica de la arquitectura: La obra de Miguel de la Colina Pujol”, Espacio, tiempo y forma. Serie VII, Historia del arte, 13, 2000, p. 414; El eco patronal, Madrid, 15-6-1929, p. 15; y Madrid Científico, Madrid, 937, 25-111917.

79 La construcción moderna, Madrid, 24, 30-12-1917, p. 186. Cfr. Boletín Oficial del Estado, Madrid, n 182, 1-7-1846, p. 5297; y "Escalafón del Cuerpo de Arquitectos de la Hacienda pública en 30 de abril de 1918”, Arquitectura y construcción, Barcelona, 1918.

${ }^{80}$ Boletín oficial de la provincia de Madrid, Madrid, n 198, 21-8-1931, p. 5. 


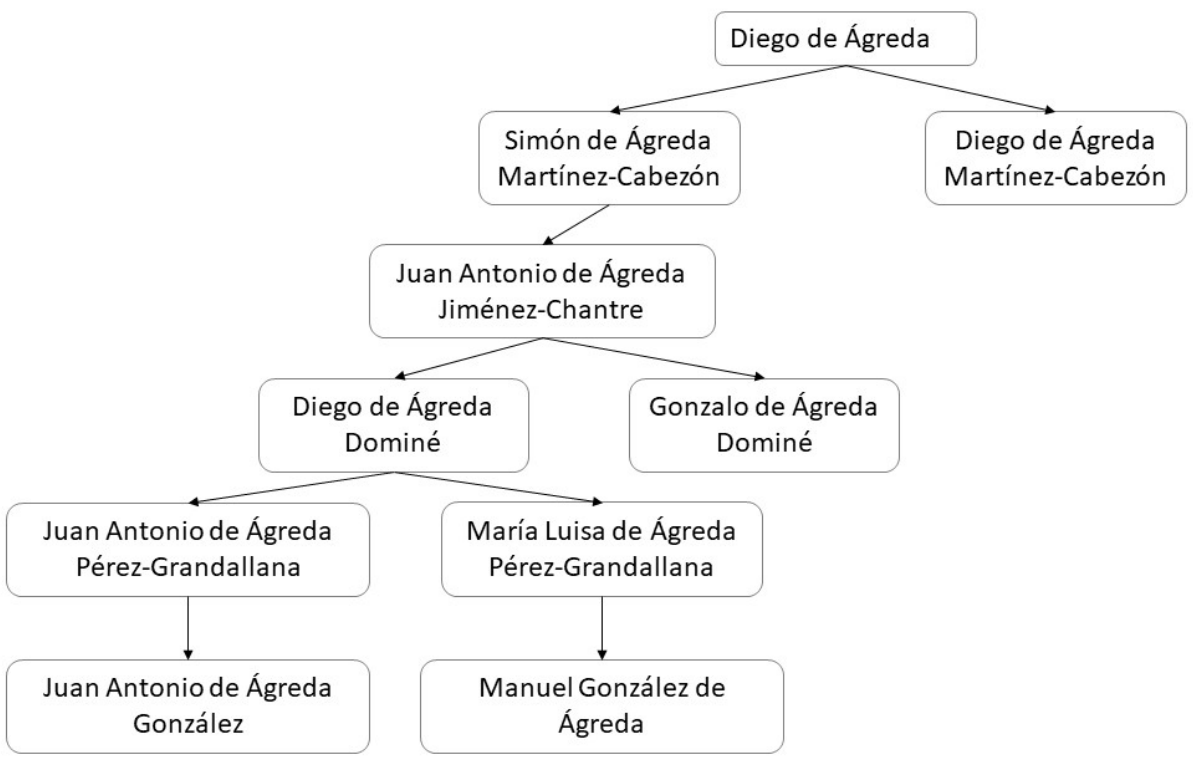

Figura 1. Árbol genealógico de la familia Ágreda. Tabla: Myriam Ferreira Fernández.

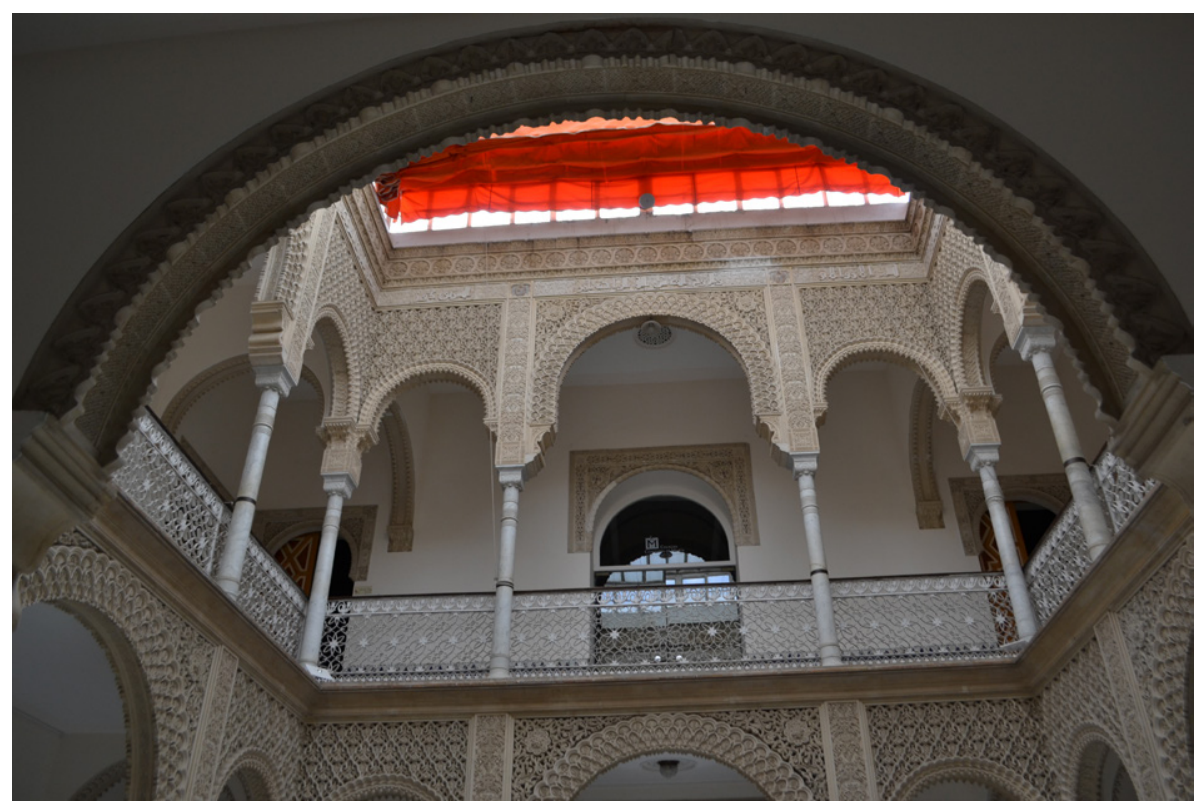

Figura 2. Patio neomudéjar, Colegio Compañía de María (antes Casa de Ágreda), hacia 1858, Jerez de la Frontera. Foto: Myriam Ferreira Fernández. 


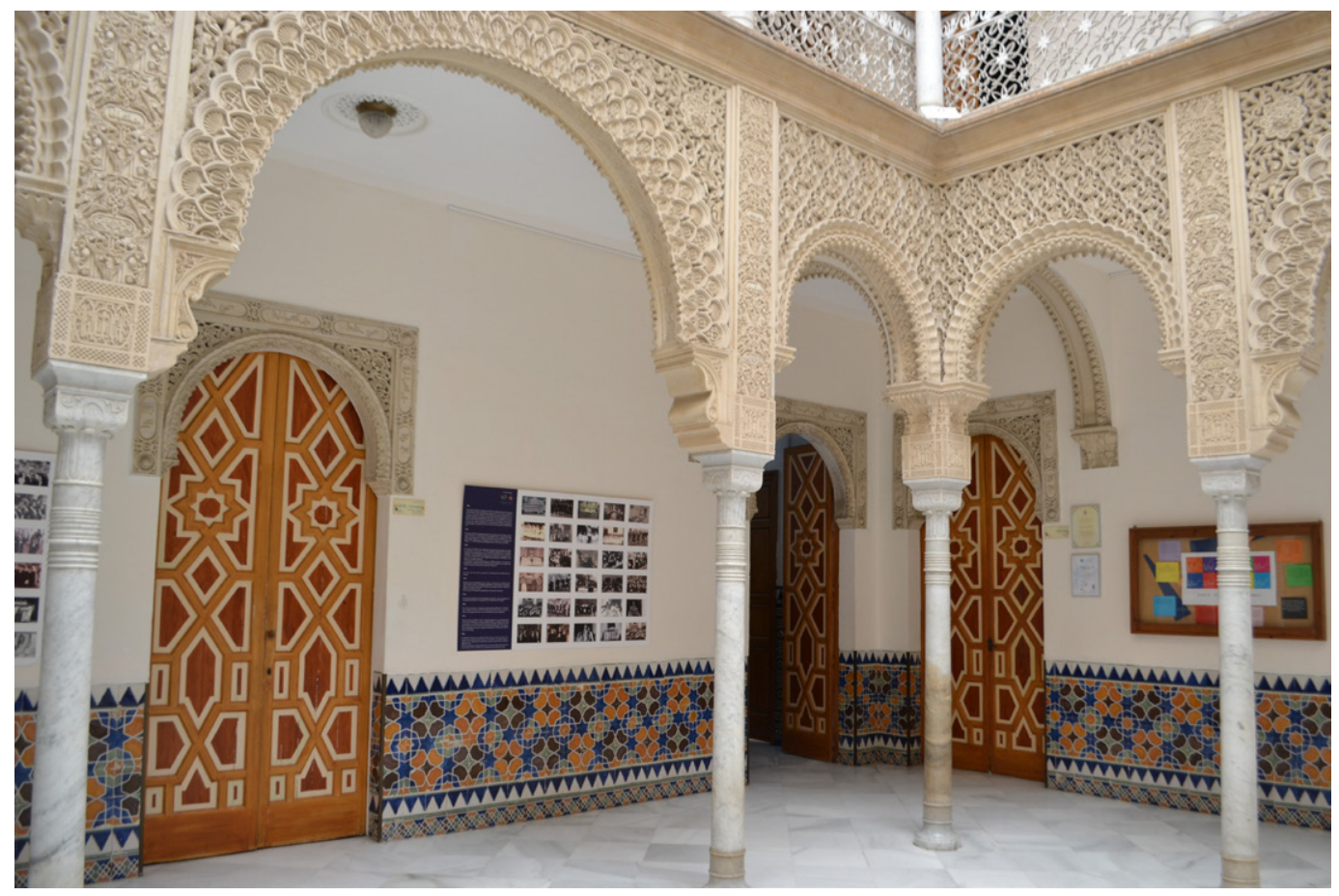

Figura 3. Patio neomudéjar, Colegio Compañía de María (antes Casa de Ágreda), hacia 1858, Jerez de la Frontera.

Foto: Myriam Ferreira Fernández. 


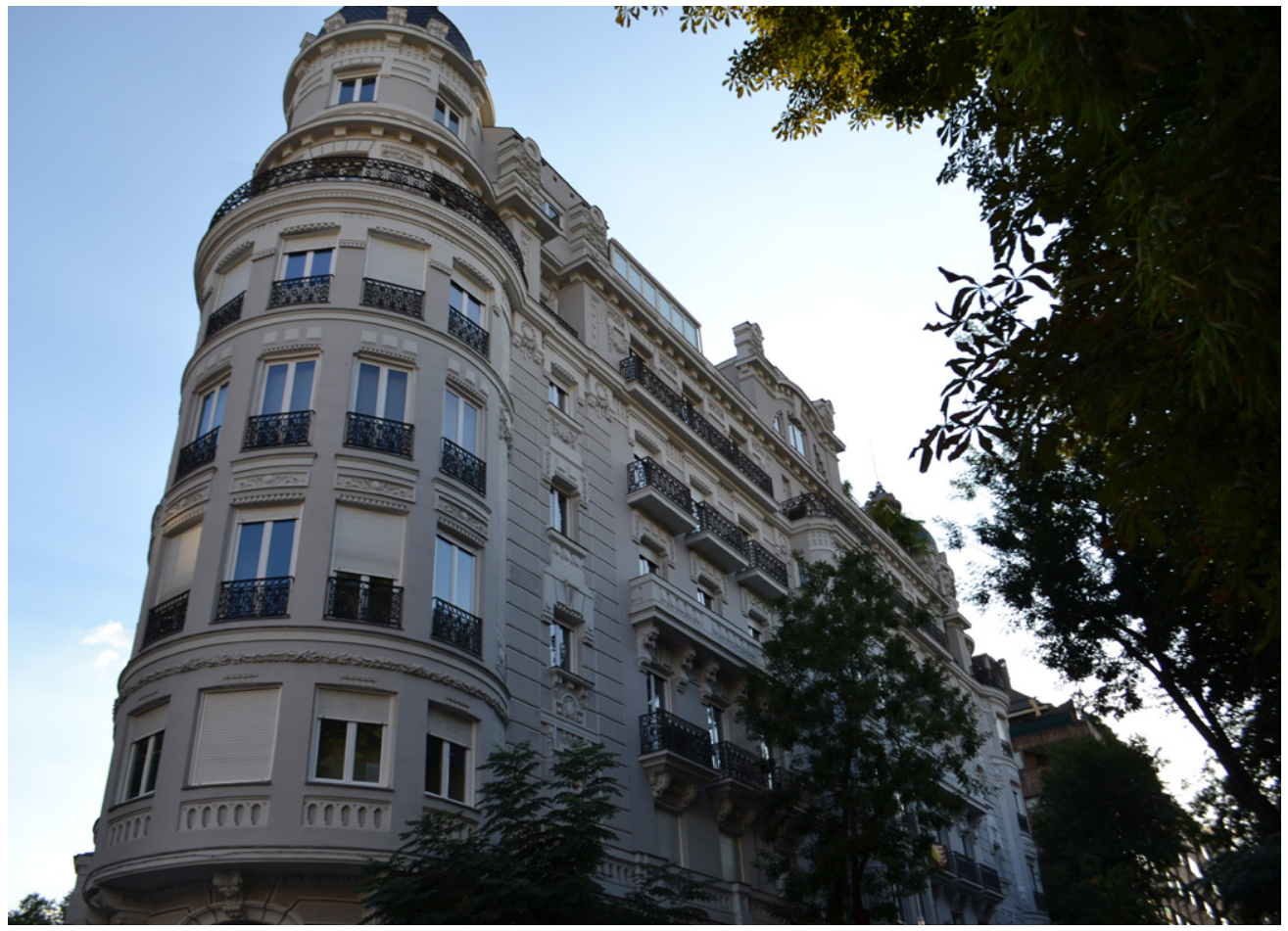

Figura 4. José Antonio de Ágreda (arquitecto), Edificio de viviendas, calle Almagro 15, hacia 1916, Madrid. Foto: Myriam Ferreira Fernández. 


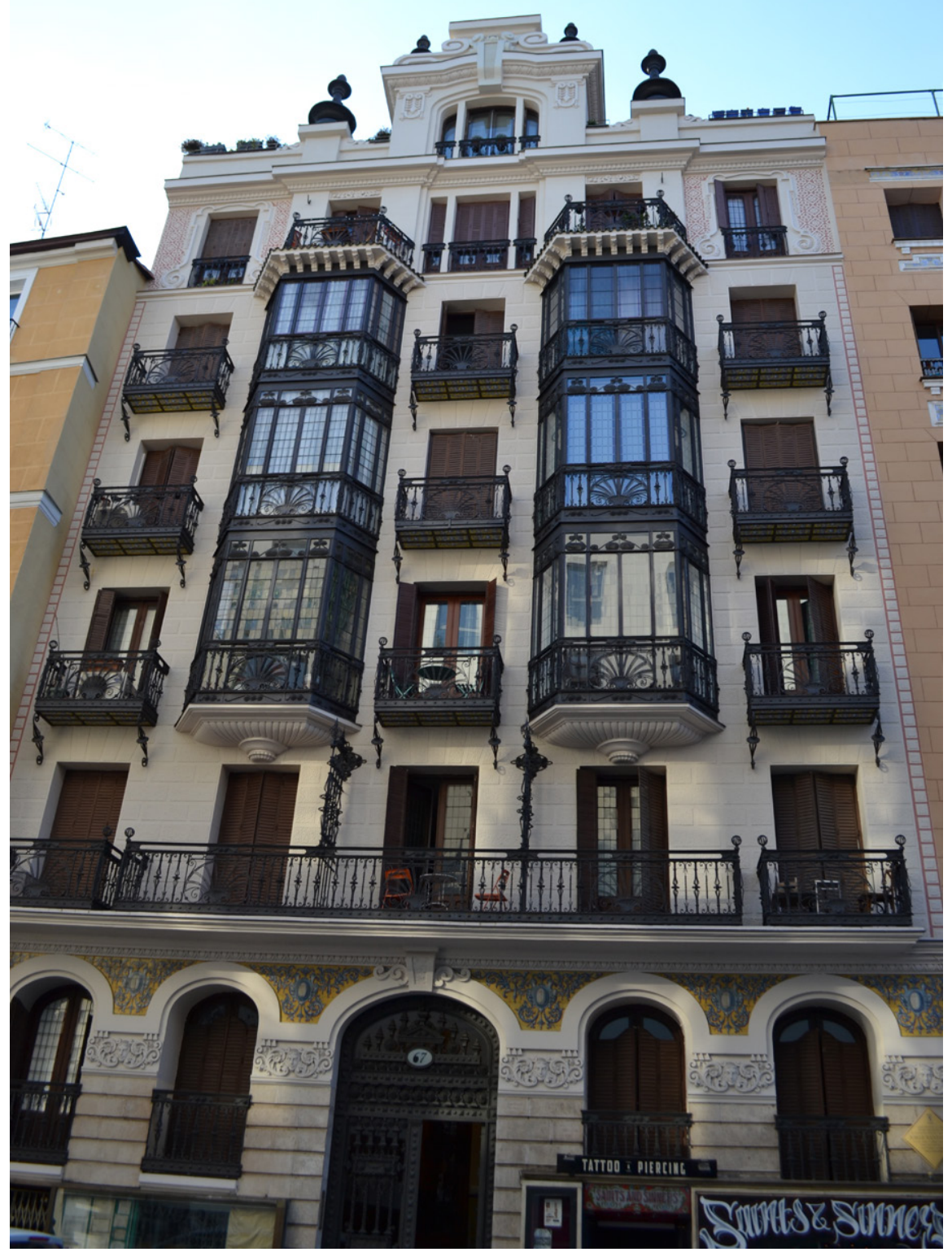

Figura 5. José Antonio de Ágreda (arquitecto), Edificio de viviendas, calle San Bernardo 67, hacia 1925, Madrid. Foto: Myriam Ferreira Fernández. 